\title{
Am I cured from cancer? A physician's personal experience
}

\author{
Itzhak Brook
}

Received: 17 December 2010 / Accepted: 3 January 2011 /Published online: 12 January 2011

(C) Springer-Verlag 2011

Five years ago I was diagnosed with hypopharyngeal carcinoma. Yet even after the cancer had been successfully treated by local excision and radiation, it was difficult to completely free myself from the apprehension that the disease would return. This fear actually materialized when I had a local recurrence 20 months later which required a total laryngectomy. Even though I had been examined once a month and had periodic diagnostic PET and CT scans, all of these failed to detect the recurrence until the tumor was large enough to be detected by endoscopy.

Despite the fact that my surgeons assured me that, after having a laryngectomy, my chances for recurrence were small, like other physicians who were faced with cancer [1, 2], my anxiety and fear did not disappear. For a while, I was afraid to make long-term plans. When confronted with simple tasks like responding to mail, writing a manuscript, or fulfilling a promise, I tried to do each task promptly, just in case I were to get sick again.

I am still apprehensive whenever I get my follow-up PET and MRI scans, and I still anxiously await the results. I sense great relief when these scans do not show new findings and feel that I have been granted a temporary lease on life - until the next tests are scheduled. My life has become a series of intervals of relative calm until the next set of scans.

Whenever I experience new symptoms, I fear the worst case scenario. I wonder if the headache or sore throat or unexplained swelling is the manifestation of the cancer, once lying in wait, now appearing locally or spreading systemically. My fear is only relieved after I undergo thorough medical evaluation.

What helps me cope with my worries is that I try to first wait a few days before seeking medical help unless there is an

\section{Brook $(\square)$}

Pediatrics Georgetown University School of Medicine,

4431 Albemarle St. NW,

Washington, DC 20016, USA

e-mail: ib6@georgetown.edu urgent problem. Fortunately, the majority of my problems and symptoms seem to disappear within this time. I also learned not to panic but to use my past experiences to rationalize and understand new symptoms and to convince myself to wait patiently for my next medical appointment.

Although I will never be completely free of the fear of cancer's return, I am hopeful that living with the uncertainty will become easier over time. I hope to adjust to the uncertainty of my future and to find a balance between fear and acceptance.

Living with an uncertain future affects the way I approach patients with serious illnesses and, I believe, has made me more sensitive and understanding. I speak now as someone who shares with my patients the uncertainty of the future and sharing my way of coping seems to help them. As a laryngectomee, my medical history is always on display in the way I look and speak. By being able to continue to help others through teaching and working, I hope to convey a message to those who face serious illness that there are ways of coping with the fear that the disease will return.

Conflict of Interest None.

\section{References}

1. Klitzman R (2008) When doctors become patients. Oxford University Press, Oxford

2. Hahn R A. Sickness and healing. Yale University. Book Crafters Chelsea, MI1995

Dr I. Brook is the author of the book My Voice: a physician's personal experience with throat cancer. The book can be read on blog site http://dribrook.blogspot.com/. 